\title{
A treasure trove of insect pathogens and other beneficial microbes
}

\author{
T.L. Nelson and S.D. Young \\ AgResearch, Private Bag 4749, Christchurch 8140, New Zealand \\ Corresponding author: tracey.nelson@agresearch.co.nz
}

AgResearch Lincoln maintains two large collections of beneficial microbes, which include insectpathogenic bacteria and fungi, and plant growth-promoting microorganisms. The collections serve as a repository for indigenous microbes of potential value as biocontrol agents and plant growth stimulants, as well as reference isolates from overseas collections. Over 3500 bacterial and 680 fungal isolates have been accessioned over a 22 -year period from most regions in New Zealand, including the Chatham Islands. Preservation of these vital genetic resources is essential for current and future bioprotection programmes, providing a source of beneficial microbes for regulation of pest threats arising through biosecurity failure, new crop management priorities and climate change. The microbes are made available for research trials/commercialisation through collaborative programmes with research organisations, such as Plant \& Food Research (fungi and bacteria for control of chorus cicada, Fuller's rose weevil, bronze beetle), Landcare Research (fungi for control of social wasps), Auckland University (effect of endophytic insect-pathogenic fungi on plant growth), and industry partners. In the last decade the collections have also played a role in confirming the presence in New Zealand of microorganisms formerly considered to be "new" under the HSNO Act.

\section{Delivering Trichoderma spp. spores via seed coating and storage stability at 20 and $25^{\circ} \mathrm{C}$}

\author{
J. Swaminathan ${ }^{1}$, M.J. Wilson ${ }^{2}$ and T.A. Jackson ${ }^{1}$ \\ ${ }^{1}$ AgResearch, Lincoln Science Centre, Christchurch, New Zealand \\ ${ }^{2}$ AgResearch, Ruakura Research Centre, Hamilton, New Zealand \\ Corresponding author: Jayanthi.Swaminathan@agresearch.co.nz
}

Trichoderma species have been reported to augment seedling establishment and provide protection from soil borne diseases. Many Trichoderma products are simply mixed into soil or compost, but seed treatment offers the potential to reduce spore application rates by directly targeting the developing rhizosphere where efficacy is realised. This study evaluated the ability of five formulations, based on oils and/or biocompatible polymers, to adhere Trichoderma spores to wheat seeds and maintain their viability in storage $\left(20\right.$ and $\left.25^{\circ} \mathrm{C}\right)$ without comprising seed quality. The five formulations varied in their initial loading (colony forming units), moisture content $(\%)$, water activity $\left(\mathrm{a}_{\mathrm{w}}\right)$ and spore germination (\%). Spore loading ranged from $2.2 \times 10^{5}-2.0 \times 10^{7}$ spores/seed, with the xanthan gumbased biopolymer formulation providing the highest loading. Best survival (43\% of initial loading) after 3 months of storage at $20^{\circ} \mathrm{C}$ was recorded in the biopolymer-based formulation followed by the polyvinyl pyrrolidone formulation (24\%). The remaining three formulations had $<10 \%$ spore survival. At $25^{\circ} \mathrm{C}$ only the biopolymer formulation had more than $10 \%$ survival compared to the initial loadings. These results indicate that Trichoderma spores can be effectively delivered onto seeds using biopolymer technology to produce shelf life stable formulations without compromising the germination quality of the seeds. 